\title{
(R)- $\left[{ }^{11} \mathrm{C}\right]$ Verapamil PET studies to assess changes in P-glycoprotein expression and functionality in rat blood-brain barrier after exposure to kainate-induced status epilepticus
}

\author{
Stina Syvänen ${ }^{1 *}$, Gert Luurtsema ${ }^{2}$, Carla FM Molthoff ${ }^{3}$, Albert D Windhorst ${ }^{3}$, Marc C Huisman ${ }^{3}$,
} Adriaan A Lammertsma ${ }^{3}$, Rob A Voskuyl ${ }^{1,4}$, Elizabeth C de Lange ${ }^{1}$

\begin{abstract}
Background: Increased functionality of efflux transporters at the blood-brain barrier may contribute to decreased drug concentrations at the target site in CNS diseases like epilepsy. In the rat, pharmacoresistant epilepsy can be mimicked by inducing status epilepticus by intraperitoneal injection of kainate, which leads to development of spontaneous seizures after 3 weeks to 3 months. The aim of this study was to investigate potential changes in Pglycoprotein (P-gp) expression and functionality at an early stage after induction of status epilepticus by kainate.

Methods: (R)- $\left[{ }^{11} C\right]$ verapamil, which is currently the most frequently used positron emission tomography (PET) ligand for determining P-gp functionality at the blood-brain barrier, was used in kainate and saline (control) treated rats, at 7 days after treatment. To investigate the effect of P-gp on $(R)-\left[{ }^{11} C\right]$ verapamil brain distribution, both groups were studied without or with co-administration of the P-gp inhibitor tariquidar. P-gp expression was determined using immunohistochemistry in post mortem brains. (R)- $\left[{ }^{11} \mathrm{C}\right]$ verapamil kinetics were analyzed with approaches common in PET research (Logan analysis, and compartmental modelling of individual profiles) as well as by population mixed effects modelling (NONMEM).
\end{abstract}

Results: All data analysis approaches indicated only modest differences in brain distribution of $(R)-\left[{ }^{11} C\right]$ verapamil between saline and kainate treated rats, while tariquidar treatment in both groups resulted in a more than 10-fold increase. NONMEM provided most precise parameter estimates. P-gp expression was found to be similar for kainate and saline treated rats.

Conclusions: P-gp expression and functionality does not seem to change at early stage after induction of anticipated pharmacoresistant epilepsy by kainate.

\section{Background}

About $30-40 \%$ of all people with epilepsy do not become fully seizure free with present medication, even when treated at the maximal tolerated dose. This pharmacoresistance is particularly prominent in partial epilepsies and some severe syndromes in infants, but essentially it can occur in nearly all types of epilepsies and epileptic syndromes. In addition, unresponsiveness in these

\footnotetext{
* Correspondence: s.syvanen@lacdr.leidenuniv.nl

'Division of Pharmacology, LACDR, Leiden University, P.O. Box 9502, 2300 RA Leiden, The Netherlands

Full list of author information is available at the end of the article
}

patients is not limited to a specific drug or drug class, but occurs with the complete range of antiepileptic drugs (AEDs) [1,2].

For a drug to exert its effect, it has to be distributed to its target at a therapeutic concentration and must be able to interact with the target. Several different mechanisms influence transport across the blood-brain barrier (BBB); i.e. passive diffusion, as well as active influx and active efflux processes. P-glycoprotein (P-gp) is one of the most important efflux transporters of exogenous substances at the BBB [3,4]. Several studies, both clinical and pre-clinical, have indicated that P-gp

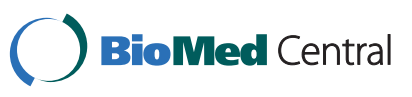

() 2011 Syvänen et al; licensee BioMed Central Ltd. This is an Open Access article distributed under the terms of the Creative Commons Attribution License (http://creativecommons.org/licenses/by/2.0), which permits unrestricted use, distribution, and reproduction in any medium, provided the original work is properly cited. 
functionality at the $\mathrm{BBB}$ may contribute to decreased target site AED concentrations in the brain [5-15]

A number of studies have shown that BBB P-gp expression is upregulated in epilepsy [10,12,16-20]. Therefore, it had been hypothesized that the observed loss of efficacy of AEDs may be caused by limited brain distribution in pharmacoresistant epilepsy caused by P-gp mediated efflux from the brain [21]. This hypothesis has been criticised by some authors [22].

Temporal Lobe Epilepsy is the most common form of epilepsy in humans and in more than half of the patients it is associated with pharmacoresistance. This condition can be mimicked in the rat by inducing status epilepticus (SE), e.g. by intraperitoneal injection of kainate [23]. In the majority of animals this leads to development of spontaneous seizures after about three weeks. However as not all patients and not all SE subjected rats become pharmacoresistant it is an important question whether this variability is related to the degree of increased P-gp expression and whether this parameter can be used as a predictor for development of pharmacoresistance.

The aim of this study was to investigate potential changes in $\mathrm{P}$-gp expression and functionality in vivo with positron emission tomography (PET). For this purpose a condition at which there is clear increased P-gp expression would be most suitable. In SE models the most prominent increase in $\mathrm{P}$-gp expression has been reported between 2-7 days after SE induction $[6,20,24]$. The well established PET ligand for determining $\mathrm{P}$-gp functionality at the $\mathrm{BBB},(R)-\left[{ }^{11} \mathrm{C}\right]$ verapamil [25-34], was used in kainate and saline treated rats, at 7 days after injection. To investigate the specific contribution of $\mathrm{P}$-gp at the $\mathrm{BBB}$, both groups were studied without or with co-administration of the P-gp inhibitor tariquidar. P-gp expression was further determined using immunohistochemistry in post mortem brains to investigate the relationship between expression and functionality. $(R)-\left[{ }^{11} \mathrm{C}\right]$ verapamil kinetics in these groups were analyzed using the common data analysis approaches used in PET (Logan analysis, compartmental modelling of individual profiles) as well as by population mixed effects modelling (NONMEM) in which sources of variability can be better addressed. In addition, covariate analysis can be integrated in the NONMEM data analysis which is a valuable tool to identify the specific origin of variability when different animal types and treatments are used.

\section{Methods}

\section{Animals}

Adult male Sprague-Dawley rats ( $\mathrm{n}=50$, Harlan, Horst, The Netherlands) weighing 200-224 g at arrival were housed in groups of 5-6 per cage until treatment. They were kept at a constant temperature of $21^{\circ} \mathrm{C}$ and at a 12 $\mathrm{h}$ light/dark cycle, in which lights were switched on at 8:00 AM. Animals had unrestricted access to food (Teklad Global 16\% Protein Rodent Diet, Harlan, Madison, WI, USA) and water. Animal procedures were performed in accordance with Dutch laws on animal experimentation. All experiments were approved by the Ethics Committee for Animal Experiments of Leiden University (approval number UDEC08178). After approximately one week of habituation and 7 days prior to PET investigation rats were treated with either kainic acid $(5 \mathrm{mg} / \mathrm{mL})$ or saline. Kainic acid was administered repeatedly as a $10 \mathrm{mg} / \mathrm{kg}(2 \mathrm{~mL} / \mathrm{kg})$ i.p. injection followed by $5 \mathrm{mg} / \mathrm{kg}(1 \mathrm{~mL} / \mathrm{kg})$ i.p. every 30-60 minutes until stage IV seizures according to Racine's scale [35] occurred, or when a total amount of $30 \mathrm{mg} / \mathrm{kg}$ kainic acid was reached. Control rats were treated with 3 saline i.p. injections using the same volumes as for the kainate treated rats, 30 minutes apart. After treatment rats were housed individually.

\section{Chemicals}

Tariquidar was obtained from API Services Inc (Westford, MA, USA), kainic acid and Triton X-100 from Sigma-Aldrich (Zwijndrecht, The Netherlands), isoflurane from Pharmachemie BV (Haarlem, The Netherlands), 5\% glucose in saline from hospital pharmacy of the University Medical Centre Leiden (UMCL, Leiden, The Netherlands), Tissue-Tek from Sakura Finitek Europe (Zoeterwoude, The Netherlands), iso-methylbutane and P-gp primary antibody C219 from VWR (Amsterdam, The Netherlands), bovine serum albumin from ICN Biomedicals (Zoetermeer, The Netherlands), rabbit and swine serum from Tebu-Bio (Heerhugowaard, The Netherlands), secondary antibody (Rabbit-anti-Mouse, bRaM) from Dako (Heverlee, Belgium) and streptavidin and 3,3-diaminobenzidine (DAB)-kit from Brunschwig Chemie Vector Labs (Amsterdam, The Netherlands). All starting materials for (R)- $\left[{ }^{11} \mathrm{C}\right]$ verapamil syntheses were obtained commercially and were of reagent grade.

\section{PET experiments}

Rats were anesthetized via a nose mask with isoflurane, $4 \%$ and $2 \%$ induction and maintenance, respectively, in oxygen $1 \mathrm{~L} /$ minute. The femoral vein and artery were cannulated 1-2 hours prior to PET scanning for administration of $(R)-\left[{ }^{11} \mathrm{C}\right]$ verapamil and tariquidar, and blood sampling, respectively.

(R)- $\left[{ }^{11} \mathrm{C}\right]$ verapamil was synthesized as previously described [36] yielding a solution of 1-3 GBq in around $10 \mathrm{~mL} 10 \%$ ethanol in saline. The specific activity was $56 \pm 26$ (mean \pm s.d.) GBq/ $\mu$ mole. Rats from the different groups were randomly assigned to experimental days and scanned in pairs for 60 minutes 
using a double LSO/LYSO layer High Resolution Research Tomograph (HRRT, CTI/Siemens, Knoxville, TN, USA) [37]. For attenuation and scatter correction, transmission scans were acquired prior to the start of the emission scan using a $740 \mathrm{MBq} 2$-dimensional (2D) fan-collimated ${ }^{137} \mathrm{Cs}(662 \mathrm{keV})$ moving point source [38]. The emission scan was started 30 seconds before an injection of $20.8 \pm 4.5 \mathrm{MBq}(0.15-0.3 \mathrm{~mL})$ no-carrier added $(R)-\left[{ }^{11} C\right]$ verapamil (Table 1$)$. Half of the rats were injected intravenously with tariquidar, 15 $\mathrm{mg} / \mathrm{kg}(3 \mathrm{~mL} / \mathrm{kg})$ dissolved in a vehicle consisting of $5 \%$ glucose in saline, as a bolus dose 20-30 minutes prior to the $(R)-\left[{ }^{11} C\right]$ verapamil injection. The other half was treated only with vehicle $(3 \mathrm{~mL} / \mathrm{kg})$. Immediately after the $(R)-\left[{ }^{11} \mathrm{C}\right]$ verapamil scan, $8.9 \pm 1.8 \mathrm{MBq}$ (0.15-0.3 mL) [ $\left.{ }^{18} \mathrm{~F}\right]$-2-fluoro-2-deoxy-D-glucose $\left({ }^{18} \mathrm{FDG}\right)$ was injected and a new 60 minutes scan was started. The purpose of the ${ }^{18} \mathrm{FDG}$ scan was to outline the brain to aid in defining regions of interest. The HRRT scanner acquires data in list mode, enabling post-scan definition of the frame sequence. The final frame sequence used for analysis was $6 \times 10,2 \times 30,3$ $\times 60,2 \times 150,2 \times 300$ and $4 \times 600$ seconds. Studies were reconstructed using an iterative $3 \mathrm{D}$ ordered-subsets weighted least-squares (3D-OSWLS) method with 8 iterations and 16 subsets [39]. No post-reconstruction filtering was applied. Point source resolution varied across the field of view from approximately 2.3 to $3.2 \mathrm{~mm}$ (FWHM) in the transaxial direction and from 2.5 to $3.4 \mathrm{~mm}$ in the axial direction [37].

During the $(R)-\left[{ }^{11} \mathrm{C}\right]$ verapamil scan, arterial blood samples of $0.1 \mathrm{~mL}$ were obtained at $0.5,1,3,5,10,15$, 20, 30, 45 and 60 minutes after injection. Plasma was obtained by centrifugation at $5000 \mathrm{rpm}$ for 5 minutes and activity in plasma and whole blood samples was measured in an automated 1282 Compugamma CS Universal Gamma Counter (LKB Wallac, Turku, Finland), cross-calibrated against the PET scanner. In addition, blood samples of $0.3 \mathrm{~mL}$ were obtained at 10,30 and 60 minutes and analysed for metabolism of $(R)-\left[{ }^{11} \mathrm{C}\right]$ verapamil. A further $0.3 \mathrm{~mL}$ blood sample for the measurement of tariquidar concentration was obtained after the end of the ${ }^{18} \mathrm{FDG}$ scan and analyzed using liquid chromatography tandem mass-spectrometry (LC/MS). Rats were euthanized under anaesthesia by decapitation immediately after the final blood sample.

\section{Metabolite analysis}

Metabolite analysis in plasma was performed as described previously [40]. In short, using solid phase extraction, three fractions were determined for each plasma sample: $(R)-\left[{ }^{11} \mathrm{C}\right]$ verapamil, $\mathrm{N}$-dealkylated products and O-demethylated products (non-polar metabolite fraction) and $\mathrm{N}$-demethylated products (polar metabolite fraction).

\section{P-glycoprotein expression}

P-gp expression in brain capillaries was measured according to a previously published protocol after some minor changes [41]. In short, after decapitation, the brain was isolated and transferred to an aluminium foil cup filled with Tissue-Tek, embedding the brain, and placed in an iso-methylbutane containing glass beaker in liquid nitrogen. After 1-2 minutes the brain was completely frozen and thereafter stored at $-80^{\circ} \mathrm{C}$ until further analysis. The frozen brains were cut in coronal sections, $30 \mu \mathrm{m}$, using a Leica CM1900 cryostat (Leica Microsystems B.V., Rijswijk, The Netherlands). The sections were post fixed in acetone and stored at $-20^{\circ} \mathrm{C}$ until immunohistological staining. Sections selected from the brain between $-2.3 \mathrm{~mm}$ to bregma, were chosen for immunohistochemistry [42].

Staining of brain sections from all rats were processed simultaneously in the same reaction trays to obtain comparable staining intensity. Sections were thoroughly washed for $3 \times 5$ minutes in $0.5 \mathrm{M}$ tris-buffered saline (TBS, $9 \% \mathrm{NaCl}, \mathrm{pH}$ 7.6) at room temperature. To inhibit endogenous peroxidase and reduce background staining, sections were incubated for 30 minutes in $0.5 \% \mathrm{H}_{2} \mathrm{O}_{2}$ in TBS. Again, sections were washed $3 \times 5$ minutes in 0.5 M TBS. To block interaction with other substrates, a solution containing $3 \%$ bovine serum albumin (BSA), $11 \%$ normal rabbit serum and $0.3 \%$ Triton $\mathrm{X}-100$, was added and incubated for 60 minutes at room

Table 1 Number of animals (n) with weight at the time of PET scanning and injected doses of (R)-[11C]verapamil and 18FDG in the different treatment groups (mean \pm s.d)

\begin{tabular}{lccccc}
\hline & $\begin{array}{c}\text { Saline and vehicle } \\
\text { treated }\end{array}$ & $\begin{array}{c}\text { Kainate and vehicle } \\
\text { treated }\end{array}$ & $\begin{array}{c}\text { Saline and tariquidar } \\
\text { treated }\end{array}$ & $\begin{array}{c}\text { Kainate and tariquidar } \\
\text { treated }\end{array}$ & $\begin{array}{c}\text { All } \\
\text { groups }\end{array}$ \\
\hline $\mathrm{n}$ & 10 & 11 & 10 & 11 & 42 \\
Body weight (g) & $327 \pm 26$ & $292 \pm 33$ & $326 \pm 25$ & $293 \pm 24$ & $308 \pm 31$ \\
$R-\left[{ }^{11}\right.$ C]verapamil & $22.3 \pm 3.9$ & $21.4 \pm 4.8$ & $22.1 \pm 3.9$ & $19.4 \pm 5.1$ & $20.8 \pm 4.5$ \\
$(\mathrm{MBq})$ & & & & & \\
${ }^{18} \mathrm{FDG}(\mathrm{MBq})$ & $9.6 \pm 2.1$ & $8.5 \pm 1.9$ & $9.3 \pm 1.6$ & $9.1 \pm 1.7$ & $8.9 \pm 1.8$ \\
\hline
\end{tabular}

Of the original 50 animals, 8 animals were discarded; 4 died as a result from the kainate treatment, 1 did not respond to kainate treatment, and 3 were excluded for technical reasons, such as movement in the scanner or extra vascular tracer injection. 
temperature. After this, sections were incubated overnight at $4{ }^{\circ} \mathrm{C}$ in 1:100 monoclonal mouse primary antibody $\mathrm{C} 219$ in carrier medium (containing 1\% BSA, 1\% rabbit serum and $0.3 \%$ Triton $\mathrm{X}-100$ in TBS). After overnight incubation, sections were washed $3 \times 10$ minutes in $0.5 \mathrm{M}$ TBS at room temperature. Next, sections were incubated for 90 minutes in 1:200 biotin-conjugate Rabbit-anti-Mouse (bRaM) secondary antibody in the same carrier solution as the primary antibody mentioned above. Sections were washed $3 \times 5$ minutes in $0.5 \mathrm{M}$ TBS and incubated for 90 minutes in 1:375 in 0.5 $M$ TBS solution, after which they were washed $3 \times 5$ minutes in 0.5 M TB ( $\mathrm{pH} 7.6$ ) instead of TBS to avoid possible interaction between saline and 3,3-diaminobenzidine (DAB). Sections were incubated for 10 minutes in DAB with $0.03 \% \mathrm{H}_{2} \mathrm{O}_{2}$ and then washed $2 \times 5$ minutes in $0.5 \mathrm{M}$ TB and $1 \times$ in ultrapurified water (ELGA, Ede, The Netherlands). Slides were air-dried and, on the next day, cover slipped with Entallan (Merck, Darmstadt, Germany).

Images of the stained sections were obtained with a Leica DM 600B microscope (Leica Microsystems). All analyses were performed using the freely available software Image J [43]. Two measurements, the P-gp labelled surface area and its optical density, were performed on two sections per animal and region in the regions of the cortex and hippocampus CA1. Both the labelled surface area and optical density value was obtained by first choosing a global threshold value, used for all slides. Only grey values above this threshold were assumed to result from P-gp staining. In the area method, the total number of pixels above the threshold was summed. For the optical density, the mean grey value was measured for each slide and the background, specific for that particular slide, was subtracted from the mean value.

\section{Data analysis}

PET image data were analyzed using the freely available software package Amide 0.8.22 [44]. Time-activity curves in whole brain where obtained by drawing a volume of interest (VOI) in 4 adjacent transaxial planes of the ${ }^{18}$ FDG images summed over 60 minutes, including cortical and central structures. The final VOI volume was $127 \mu \mathrm{L}$. Other VOIs were drawn in cerebellum (3 planes) and liver (3 planes), resulting in VOI volumes of 49 and $57 \mu \mathrm{L}$, respectively. Next, VOIs were transferred to the dynamic $(R)-\left[{ }^{11} \mathrm{C}\right]$ verapamil image sequence, generating corresponding time-activity curves. Whole brain and cerebellum time-activity curves were used for analysis of $(R)-\left[{ }^{11} \mathrm{C}\right]$ verapamil kinetics in brain. To correct for an intravascular contribution, radioactivity measured in whole blood was exponentially interpolated to obtain blood radioactivity values at each mid frame time point and then subtracted from the brain time-activity curves, assuming that cerebral blood volume was $3 \%$ of the total brain volume [45].

Liver time-activity curves, obtained from the PET images, and plasma time-activity curves, obtained from the plasma samples, were checked for any irregularities pointing to e.g. extravascular injection. If irregularities were found, the animal was excluded from further analysis.

Plasma time-activity curves were corrected for tracer metabolism before they were used as input for kinetic modelling. As metabolite fractions were not measured at each plasma time point, linear regression was used to estimate the fraction of intact $(R)-\left[{ }^{11} \mathrm{C}\right]$ verapamil at all blood sampling time points. The activity in each plasma sample was then multiplied with the fraction of intact (R)- $\left[{ }^{11} \mathrm{C}\right]$ verapamil. Two types of corrections were used: (1) complete metabolite correction and (2) correction only for polar metabolites. The rationale for the second correction was that non-polar metabolites of $(R)-\left[{ }^{11} \mathrm{C}\right]$ verapamil are thought to have similar kinetics as (R)- $\left[{ }^{11} \mathrm{C}\right]$ verapamil itself [46]. Mathematically, this is described by the following equations:

$$
C_{p}=C_{m} * f
$$

where $C_{p}$ is the concentration of the plasma input function as used for modelling purposes, $C_{m}$ the (total) plasma concentration as measured in the gamma counter and $f$ the fraction of unchanged $(R)-\left[{ }^{11} \mathrm{C}\right]$ verapamil. Here, $f$ is a value between 0 and 1 , given by:

$$
f=\frac{(R)-\left[{ }^{11} \mathrm{C}\right] \text { verapamil activity }}{\text { Total plasma activity }}
$$

for complete metabolite correction, or

$$
\begin{aligned}
& f=\frac{(R)-\left[{ }^{11} \mathrm{C}\right] \text { verapamil activity }}{\text { Total plasma activity }} \\
& +\frac{\left[{ }^{11} \mathrm{C}\right] \text { non }- \text { polar metabolite activity }}{\text { Total plasma activity }}
\end{aligned}
$$

for correction of polar metabolites only

Finally, data were analysed without a correction for labelled metabolites, i.e. assuming $f=1$. For modelling of individual profiles (see section below), $\mathrm{C}_{\mathrm{p}}$ was linearly interpolated to obtain plasma activity values at the same time points as in the brain, i.e. the mid frame time points. 


\section{Modelling of individual profiles}

The models described in this section were fitted to individual data from each animal. To obtain a model-independent estimate of the brain-to-blood partition coefficient $\mathrm{K}_{\mathrm{p}}$ (often referred to as volume of distribution, $\mathrm{V}_{\mathrm{T}}$, in PET literature), Logan graphical analysis [47] was used. In addition, the influx rate constant $K_{1}$ was estimated from Logan analysis. PET data were also fitted using standard compartmental models, i.e. a 1 tissue (brain) compartment model with 2 rate constants (1T2k) and a 2 tissue (brain) compartment model with 4 rate constants $(2 \mathrm{~T} 4 \mathrm{k})$ [48]. In the $1 \mathrm{~T} 2 \mathrm{k}$ model the two rate constants describe transport across the $\mathrm{BBB}$, whilst the $2 \mathrm{~T} 4 \mathrm{k}$ model also includes two rate constants describing the exchange between fast and slow equilibrating compartments in the brain. The model with the lowest value of the Akaike information criterion (AIC) was considered the best [49]. Rate constants obtained for the different rat groups were compared using a t-test with Bonferroni correction for multiple comparisons. Dedicated analysis programs were written within the MATLAB 6 (Mathworks, Natick, MA, USA) software environment.

\section{Population mixed effects modelling}

Nonlinear mixed effects modelling, using NONMEM VI (GloboMax LLC, Hanover, MD, USA), provide a tool for analyzing repeated measurements data in which the relationship between the explanatory and response variables can be modeled as a single function, allowing the parameters to differ between individuals. In addition, these techniques recognize that the variability associated with the response variable for a given individual may depend on the response value in a way that is similar for all individuals. This could be due, for example, to properties associated with measurement error.

Data from all rats was processed simultaneously. The subroutine ADVAN 9 and first-order conditional estimation with interaction were used throughout the modelling procedure. Model selection was based on the objective function value (OFV; with the lowest value corresponding to the best model), model parameter uncertainty and visual analysis using software Xpose 4 [50] implemented in R 2.7.1 (The R foundation for Statistical Computing) accessed from Census [51]. For nested models, OFV reductions of 3.83, 6.63 and 10.83 units correspond to improved fits at $\mathrm{p}<0.05, \mathrm{p}<0.01$ and $\mathrm{p}<0.001$ levels, respectively. The inter-individual variation of a parameter was described by the exponential variance model:

$$
\theta_{i}=\theta_{\text {pop }} * \exp \left(\eta_{i}\right)
$$

where $\theta_{i}$ is the parameter in the $\mathrm{i}^{\text {th }}$ animal, $\theta_{\text {pop }}$ the parameter in a typical animal and $\eta_{i}$ the inter-animal variability, which is assumed to be normally distributed around zero with a standard deviation $\omega$. Equation (3) provides a means to distinguish the parameter value for the $i^{\text {th }}$ animal from the typical value predicted from the regression model.

The NONMEM model was constructed in two steps. In the first step, a pharmacokinetic model for $(R)-\left[{ }^{11} \mathrm{C}\right]$ verapamil plasma concentrations was developed. One, two and three compartment models were evaluated. Treatment (tariquidar or vehicle), rat group (saline or kainate treated) and animal weight were defined as covariates to study their effects on the parameter estimates. In the second step the model was extended to include brain $(R)-\left[{ }^{11} \mathrm{C}\right]$ verapamil PET data, while allowing the plasma estimates to freely change from the values obtained in the first step. Again, one and two compartment models were evaluated, and treatment, rat group and animal weight were included as covariates. A stepwise forward addition and backward deletion approach was applied to test the significance for covariate inclusion. Proportional error models were included for the residual variability.

\section{Results}

\section{Kainate treatment}

Kainic acid treatment resulted in stage IV-V seizures in all rats, except one who did not show any epileptic behaviour after $30 \mathrm{mg} / \mathrm{kg}$ kainic acid. Typically 3 injections, i.e. $20 \mathrm{mg} / \mathrm{kg}$, were needed and SE was usually reached within 20 minutes after the last injection. Rats usually displayed seizures for 1-2 hours. The seizures were not interrupted by any anti-epileptic drug. Due to the design of this study it was not possible to determine whether these animals eventually would have developed spontaneous epilepsy, but the signs and symptoms during and after SE were very similar to those observed in previous studies where animals did develop epilepsy. Four rats died as a result of kainic acid treatment. The final numbers of successfully scanned rats in each group, together with their average weight on the experimental day, are shown in Table 1.

\section{(R)- $\left[{ }^{11} \mathrm{C}\right]$ verapamil metabolite analysis}

Metabolite analysis showed no differences between plasma metabolite fractions in the various groups of rats. The fractions of intact $(R)-\left[{ }^{11} \mathrm{C}\right]$ verapamil were (mean \pm s.d.) $0.79 \pm 0.05,0.58 \pm 0.07$ and $0.39 \pm 0.08$ at 10,30 and 60 minutes, respectively. The summed fractions of intact $(R)-\left[{ }^{11} \mathrm{C}\right]$ verapamil and its ${ }^{11} \mathrm{C}$ labelled non-polar labelled metabolites were $1.00 \pm 0.00,0.97 \pm$ $0.02,0.91 \pm 0.06$ at 10,30 and 60 minutes, respectively. For tariquidar treated rats, complete metabolite correction of the plasma curve (Material and methods, Equation $2 \mathrm{a}$ ) resulted in better fits and less variation in 
parameter estimates than either a correction for polar metabolite alone (Equation 2b) or no correction at all. For vehicle rats, the different corrections resulted in only minor differences. In the final analysis complete metabolite correction (Equation 2a) was used and all estimates reported are based on this correction.

\section{(R)- $\left[{ }^{11} \mathrm{C}\right]$ verapamil brain uptake without tariquidar} treatment

Uptake of $(R)-\left[{ }^{11} C\right]$ verapamil in the brain was homogeneous, but time-activity curves for the cerebellum VOI showed somewhat faster uptake and washout than those for the whole brain VOI (data not shown). Modelling was performed using the whole brain VOI time-activity curves. Average whole brain time-activity curves, expressed in standardized uptake value (SUV, radioactivity normalized to injected dose and animal weight), are shown in Figure 1. Three of the scanned rats were excluded due to movement in the scanner $(n=1)$ or extravascular tracer injection $(n=2)$.

No difference in brain to blood concentration ratio, $K_{p}$, was found between saline treated control and kainate treated rats. All modelling approaches resulted in similar estimates of $K_{p}$, with the 1 T2 $k$ model providing lower $K_{p}$ estimates than Logan analysis, the 2T4k model and the two compartment population model (Table 2). The different modelling approaches (see Material and Methods) also resulted in similar $K_{1}$ estimates with no significant differences between saline and kainate treated rats. AIC values were used to compare the performance of the $1 \mathrm{~T} 2 \mathrm{k}$ and $2 \mathrm{~T} 4 \mathrm{k}$ models. In general, AIC values were similar for $1 \mathrm{~T} 2 \mathrm{k}$ and $2 \mathrm{~T} 4 \mathrm{k}$ models, with an average difference of $0.5 \%$ in favour of the $1 \mathrm{~T} 2 \mathrm{k}$ model. Visual inspection, however, indicated that, in most cases, better fits were

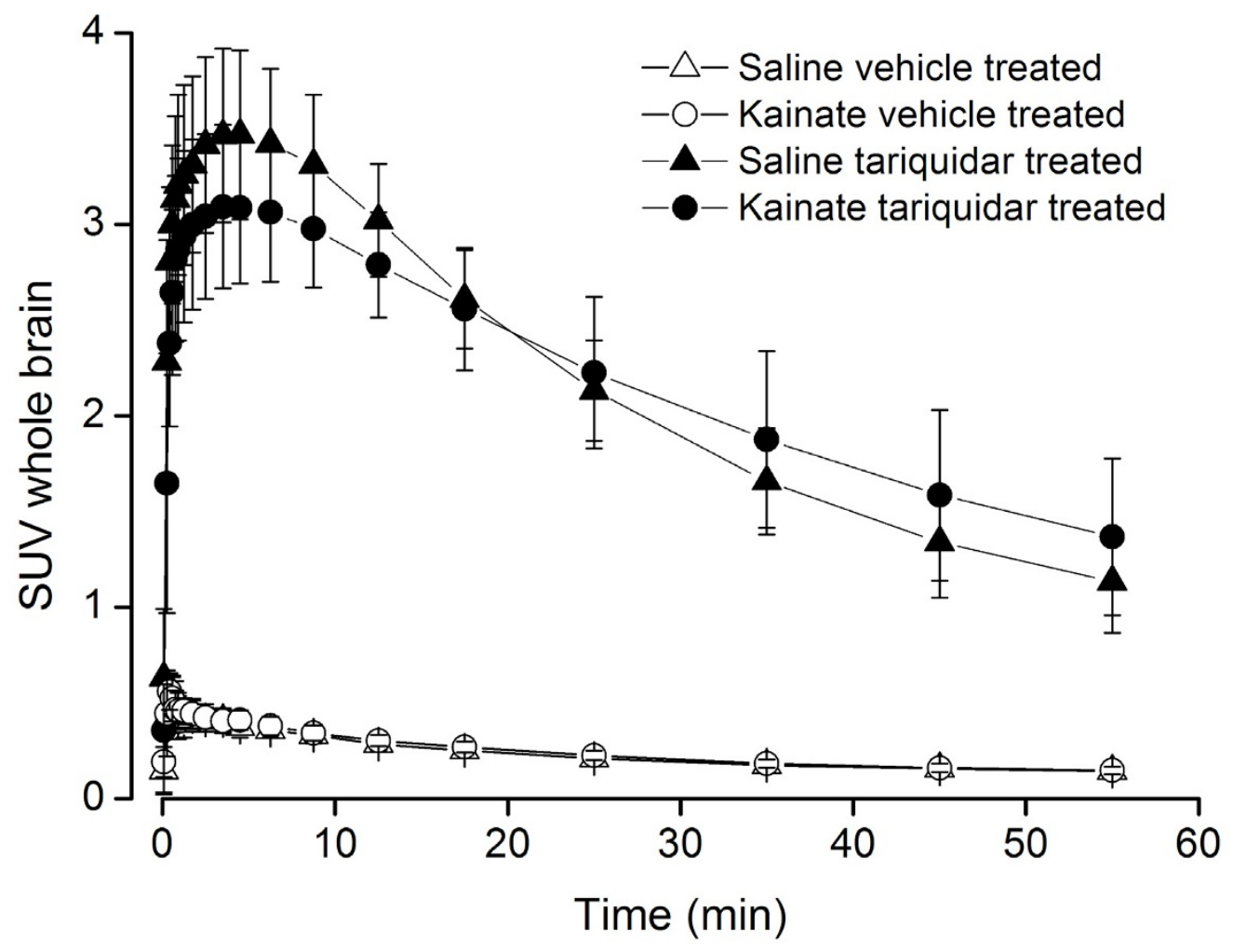

Figure 1 Mean whole brain uptake of $(R)-\left[{ }^{11} \mathrm{C}\right]$ verapamil, expressed as SUV (radioactivity normalized to injected dose and rat weight), as function of time in the four rat groups. Vertical bars represent standard deviation. No difference was found in the profiles between vehicle co-administered saline and kainate treated animals. Somewhat slower kinetics was observed in the kainate treated compared to the saline treated rats that were also co-administered with tariquidar. 
Table 2 Mean ( \pm standard deviation) of (R)-[11C]verapamil parameter estimates for the different rat groups obtained using various modelling approaches $\left({ }^{* * *} p<0.001,{ }^{* *} p<0.01,{ }^{*} p<0.05\right.$., not significant (ns) $\left.p>0.05\right)$

\begin{tabular}{|c|c|c|c|c|c|c|c|c|}
\hline \multirow[b]{2}{*}{$\begin{array}{l}\text { Parameter } \\
\text { estimates }\end{array}$} & \multicolumn{3}{|c|}{ Vehicle treated } & \multicolumn{3}{|c|}{ Tariquidar treated } & \multirow[b]{2}{*}{$\begin{array}{c}\text { Group } 1 \text { vs } \\
\text { Group } 3\end{array}$} & \multirow[b]{2}{*}{$\begin{array}{c}\text { Group } 2 \\
\text { Group }\end{array}$} \\
\hline & $\begin{array}{l}\text { Group } \\
\text { 1: } \\
\text { Saline }\end{array}$ & $\begin{array}{l}\text { Group 2: } \\
\text { Kainate }\end{array}$ & $\begin{array}{l}\text { Group } 1 \text { vs } \\
\text { Group } 2\end{array}$ & $\begin{array}{l}\text { Group 3: } \\
\text { Saline }\end{array}$ & $\begin{array}{l}\text { Group 4: } \\
\text { Kainate }\end{array}$ & $\begin{array}{l}\text { Group } 3 \text { vs } \\
\text { Group } 4\end{array}$ & & \\
\hline \multicolumn{9}{|l|}{ Model - Logan } \\
\hline $\begin{array}{l}\mathrm{K}_{1}\left(\mathrm{~mL} \cdot \mathrm{mL}^{-1} \cdot \mathrm{min}^{-}\right. \\
\left.{ }^{-}\right)\end{array}$ & $\begin{array}{c}0.06 \\
(0.02)\end{array}$ & $0.06(0.02)$ & ns & $0.85(0.16)$ & $0.74(0.18)$ & ns & $* * *$ & $* * *$ \\
\hline $\mathrm{K}_{\mathrm{p}}\left(\mathrm{mL} \cdot \mathrm{mL}^{-1}\right)$ & $\begin{array}{c}1.04 \\
(0.19)\end{array}$ & $1.00(0.13)$ & ns & 10. $9(1.3)$ & $11.7(1.3)$ & ns & $* * *$ & $* * *$ \\
\hline
\end{tabular}

\section{Model - 1T2K}

$K=\left(m L \cdot \mathrm{mL}^{-1} \cdot \mathrm{min}\right.$

$\mathrm{K}_{1}\left(\mathrm{~mL} \cdot \mathrm{mL}^{-1} \cdot \mathrm{min}^{-} \quad 0.06\right.$

$\mathrm{k}_{2}\left(\mathrm{~min}^{-1}\right)$

$\mathrm{K}_{\mathrm{p}}\left(\mathrm{mL} \cdot \mathrm{mL}^{-1}\right)$

\section{Model -2T4K}

$K_{1}\left(\mathrm{~mL} \cdot \mathrm{mL}^{-1} \cdot \mathrm{min}^{-}\right.$

1)

$\mathrm{k}_{2}\left(\min ^{-1}\right)$

$k_{3}\left(\min ^{-1}\right)$

$k_{4}\left(\min ^{-1}\right)$

$\mathrm{K}_{\mathrm{p}}\left(\mathrm{mL} \cdot \mathrm{mL}^{-1}\right)$

Model -2 comp PopPK ${ }^{a}$

$\mathrm{K}_{1}\left(\mathrm{~mL} \cdot \mathrm{mL}^{-1} \cdot \mathrm{min}^{-} \quad 0.1\right.$

$\left.{ }^{1}\right)$

$\mathrm{k}_{2}\left(\mathrm{~min}^{-1}\right) \quad 0.25$

$k_{3}\left(\min ^{-1}\right) \quad 0.10$

$k_{4}\left(\min ^{-1}\right)$

$\mathrm{K}_{\mathrm{p}}\left(\mathrm{mL} \cdot \mathrm{mL}^{-1}\right)$

0.06

\subsection{7}

(0.04)

0.16
$(0.15)$

0.11

(0.14)

1.08

(1.56)

1.17
$(0.65)$
$0.08(0.04)$

$0.24(0.26)$

$0.19(0.30)$

$0.49(0.96)$

$1.12(0.40)$

$0.10(0.02)$

$0.25(0.08)$

$0.10(0.03)$

$0.06(0.02)$

$0.97(0.21)$ ns

ns

ns

ns

ns

ns

ns

ns

(0.02)

${ }^{a}$ rate constants were calculated based on the model estimates shown in Table 3 as follows: $\mathrm{K}_{1}=\mathrm{Q}_{\mathrm{in}} / \mathrm{N}_{\mathrm{c}}\left(\mathrm{V}_{\mathrm{c}} / \mathrm{V}_{\mathrm{br} 1+2}\right), \mathrm{k}_{2}=\mathrm{Q}_{\mathrm{out}} / \mathrm{N}_{\mathrm{br} 1}, \mathrm{k}_{3}=\mathrm{Q}_{\mathrm{br}} / \mathrm{N}_{\mathrm{br} 1}$ and $\mathrm{k}_{4}=\mathrm{Q}_{\mathrm{br}} / \mathrm{N}_{\mathrm{br} 2}$. The population model is shown in Figure 3. The reader is referred to Gunn, et al. (2001) for a description of the 1T2k and 2T4k models and to Logan, et al. (1990) for a description of the Logan analysis.

obtained using the 2T4k model (Figure 2). Inter-animal variation in the parameter estimates, however, was larger for the $2 \mathrm{~T} 4 \mathrm{k}$ model than for the $1 \mathrm{~T} 2 \mathrm{k}$ model.

\section{P-gp blockage by Tariquidar co-administration}

Tariquidar plasma concentrations were not significantly different between saline and kainate treated rats. At 2 hours after tariquidar administration the concentrations (mean \pm s.d.) were $1.8 \pm 0.3$ and $1.6 \pm 0.3 \mu \mathrm{g} / \mathrm{mL}$ in the saline and kainate group, respectively. Tariquidar co-administration resulted in a 10- to 11-fold increase in the brain-to-plasma concentration ratio, $K_{p}$, regardless of the modelling approach used. This increase was of similar magnitude for whole brain and cerebellum. In addition, after tariquidar treatment, there was no significant difference in $K_{p}$ between saline and kainate treated rats. Both the $1 \mathrm{~T} 2 \mathrm{k}$ and the $2 \mathrm{~T} 4 \mathrm{k}$ model showed that after tariquidar co-administration, the $(R)-\left[{ }^{11} \mathrm{C}\right]$ verapamil transport into the brain, $K_{1}$ was strongly increased, both in kainate treated and saline treated rats (Table 2). However 

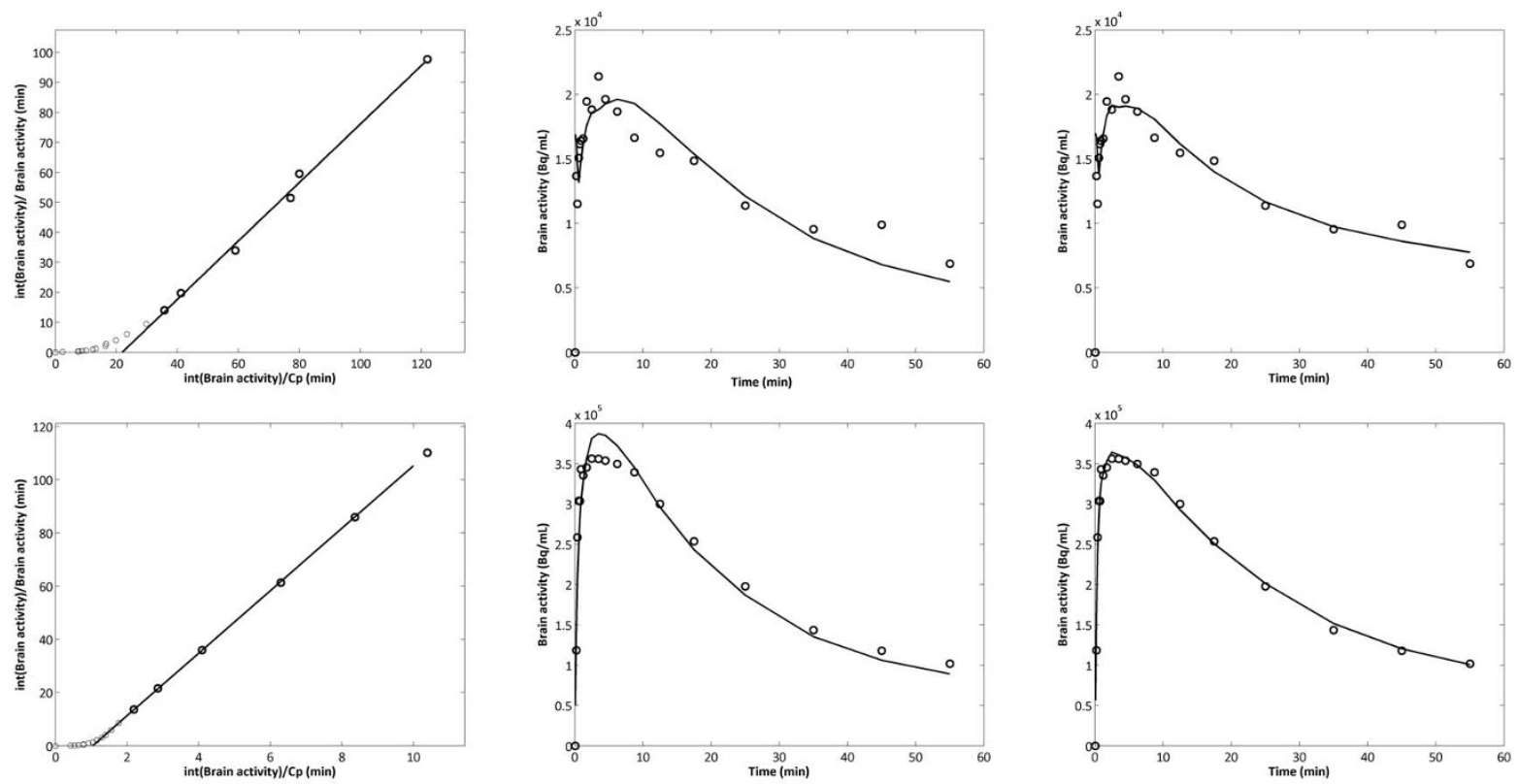

Figure 2 Logan (left), 1T2k (middle) and 2T4k (right) fits for a vehicle (upper panel) and a tariquidar (lower panel) co-administered saline treated rat. Circles represent measured concentrations, solid lines best fits. The $2 T 4 \mathrm{k}$ model resulted in better fits than the $1 T 2 \mathrm{k}$ model for most of the rats.

$\mathrm{K}_{1}$ did not increase to the same extent in both groups, as it was significantly $(\mathrm{p}<0.001)$ lower in kainate compared to saline treated rats. In addition, the transport out of the brain, $\mathrm{k}_{2}$, was lower in tariquidar co-administered kainate treated rats compared with the tariquidar co-administered saline treated rats, but the difference did not reach significance. AIC values were lower $(2.6 \%)$ for the $2 \mathrm{~T} 4 \mathrm{k}$ model and visual inspection showed that $2 \mathrm{~T} 4 \mathrm{k}$ fits were better than 1T2k fits (Figure 2).

Population mixed effects modelling of plasma and brain kinetics with and without tariquidar co-administration

$(R)-\left[{ }^{11} \mathrm{C}\right]$ verapamil kinetics in both plasma and brain were further studied using mixed effects modelling by NONMEM. The final model is shown in Figure 3 and the model diagnostics plots are shown in Figure 4. Complete metabolite corrected plasma curves were best described with a three compartment model. There were no significant differences between kainate and saline treated rats (Table 3). Tariquidar co-administration however, resulted in an increased volume of distribution (the pharmacokinetic term) for one of the peripheral compartments $\left(\mathrm{V}_{\mathrm{p} 1}\right)$, whilst rat body weight affected clearance $(\mathrm{CL})$. Thus, tariquidar co-administration and rat weight were included as covariates for $\mathrm{V}_{\mathrm{p} 1}$ and $\mathrm{CL}$, respectively.
Brain kinetics were best described with a two compartment model. Two covariates were included in the brain model: tariquidar co-administration and rat group, i.e. saline or kainate treated. Tariquidar co-administration increased both the transport into the brain, $Q_{i n}$, and the volume of distribution in the brain, $\mathrm{V}_{\mathrm{br} 1}$, of (R)- $\left[{ }^{11} \mathrm{C}\right]$ verapamil, whilst rat group affected only the $\mathrm{V}_{\mathrm{br} 1}$ estimate. Both tariquidar co-administration and rat group were treated as categorical covariates, i.e. they were assigned a value of 0 or 1 . The final equations, including covariates were defined as:

$$
\begin{gathered}
\theta_{i}=\theta_{\text {pop }} *(\text { weight } / 308.4)^{\theta_{\text {cov ariate }}} \\
\theta_{i}=\theta_{\text {pop }} * \theta_{\text {cov ariate }} \text { COVARIATE }(1 \text { or } 0)
\end{gathered}
$$

Where $\theta_{\text {covariate }}$ is the estimated covariate for weight influence on CL (Equation 4) and for tariquidar coadministration or rat group influence on $\mathrm{V}_{\mathrm{p} 1}$, $\mathrm{Q}_{\mathrm{in}}$ or $\mathrm{V}_{\mathrm{br} 1}$ (Equation 5). In Equation 5, tariquidar co-administration and kainate treatment were assigned the value of 1 , while vehicle co-administration and saline treatment were assigned the value of 0 . Thus, $\theta_{\text {covariate }}$ is the fractional change caused by kainate treatment or tariquidar co-administration. 


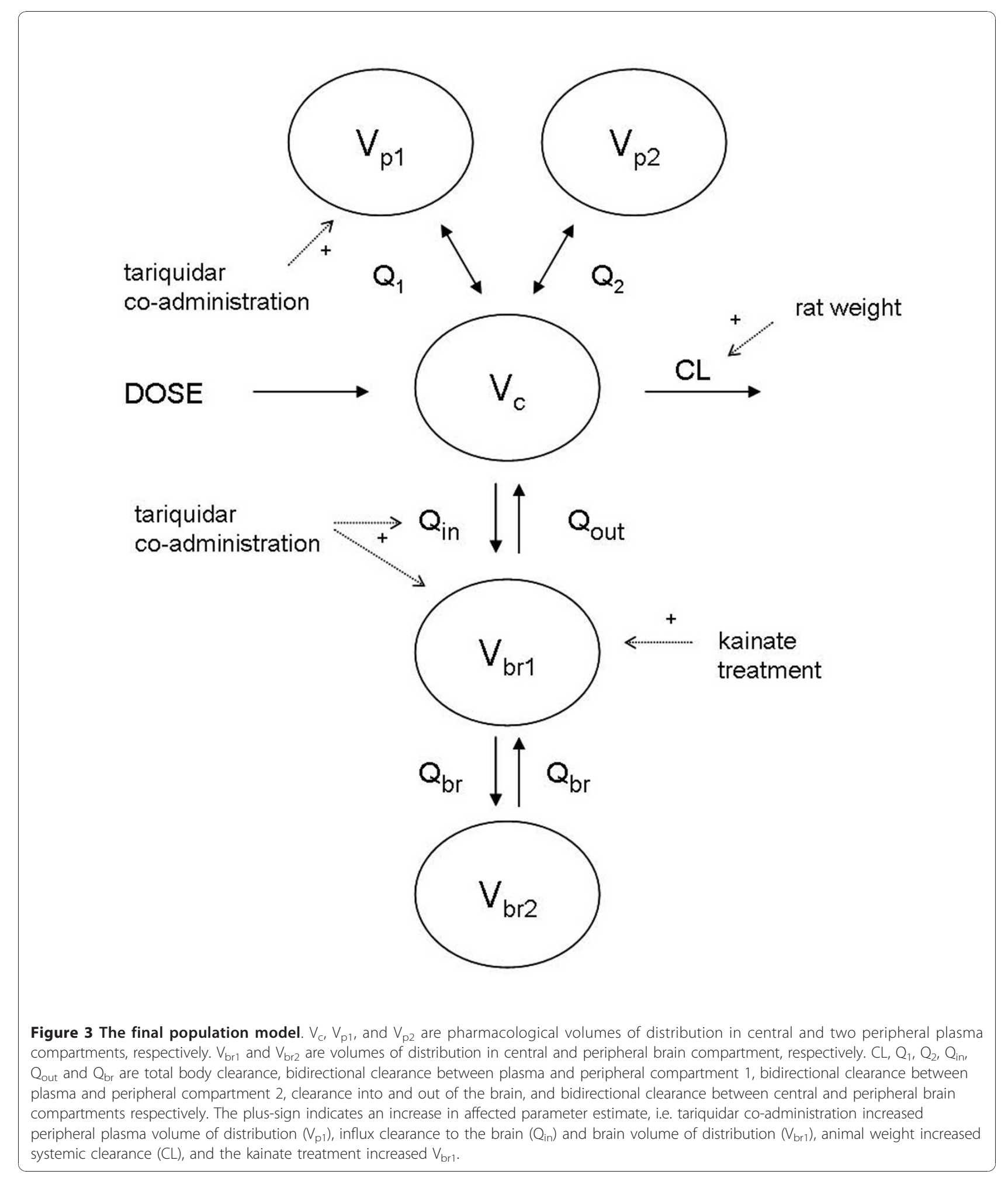

Inter-individual variation was investigated for all parameters, but incorporated only for those parameters for which it significantly $(\triangle \mathrm{OFV}>3.83)$ improved the model (Table 3). Reparameterisation of CL into rate constants (Table 2) was used to allow for comparison with the other modelling approaches, and showed that tariquidar co-administration increased the rate constant for $(R)-\left[{ }^{11} \mathrm{C}\right]$ verapamil transport into the brain, $\mathrm{K}_{1}$, and 


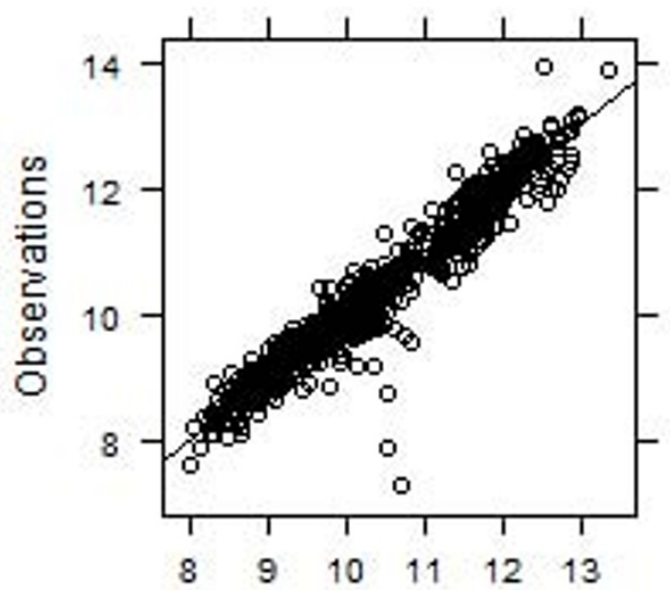

Population predictions

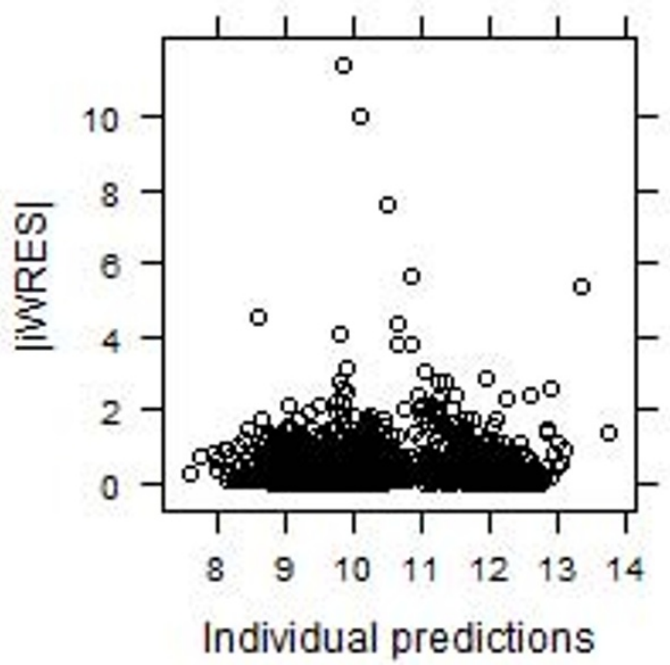

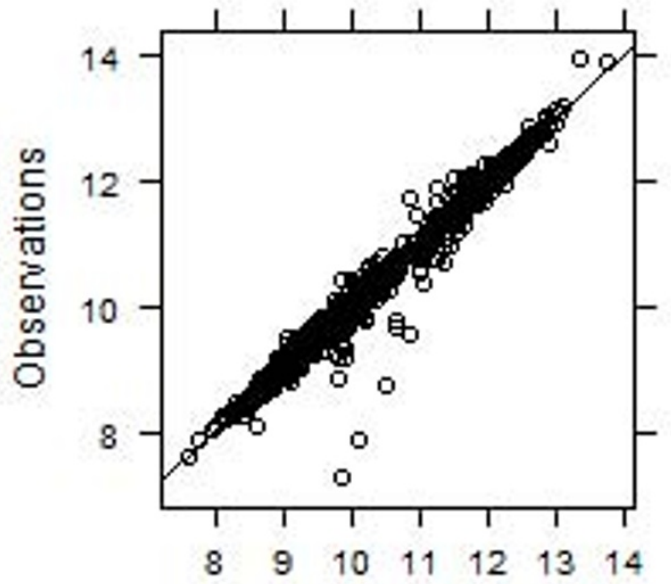

Individual predictions

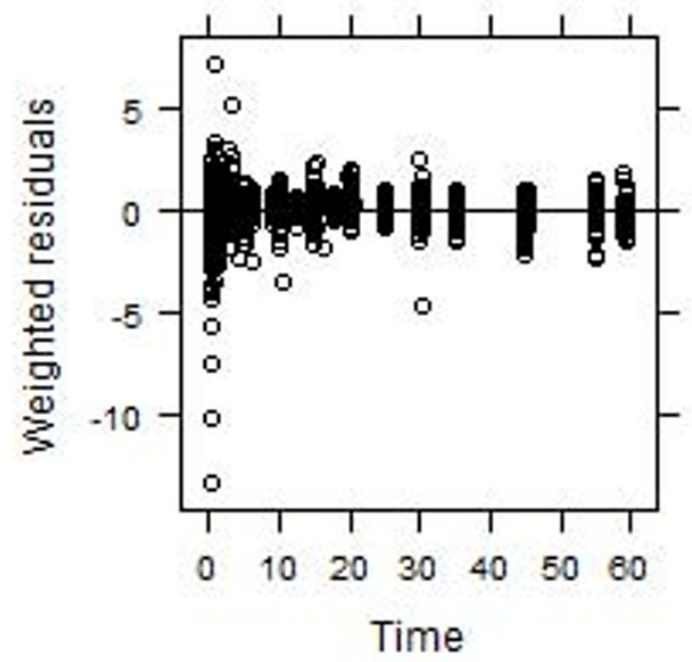

Figure 4 Diagnostic plots for the final population model including both brain and plasma $(R)-\left[{ }^{11} \mathrm{C}\right]$ verapamil concentrations. All dots represent individual data points and the lines (upper panels) identity lines. Observed versus population and individual predictions are shown in the upper panels, respectively. Most of the data points are randomly distributed around the line of identity which indicates that the model describes the concentrations adequately. Absolute individual weighted residuals versus individual predictions and weighted residuals versus time are shown in the lower panels. Except for some outliers at early time points, most residuals are clustered around zero.

decreased its rate constant for transport out of the brain, $\mathrm{k}_{2}$, in both saline and kainate treated rats. In addition, since kainate treated rats had a higher brain distribution volume $\left(\mathrm{V}_{\mathrm{br} 1}\right), \mathrm{k}_{2}$ was reduced in kainate compared to saline treated rats. All these findings were in accordance with those obtained using the other modelling approaches, but the variation in parameter estimates was smaller.

\section{${ }^{18}$ FDG brain uptake}

At 60 minutes after injection, ${ }^{18}$ FDG brain uptake was significantly decreased in kainate treated rats compared to saline treated rats $(\mathrm{p}<0.05)$, with SUV (mean \pm s.d.) of $2.0 \pm 0.4$ and $1.6 \pm 0.3$, respectively. No change in ${ }^{18}$ FDG brain uptake could be demonstrated after tariquidar co-administration. SUV was $1.8 \pm 0.4$ in both groups. The same trend was seen in the cerebellum. 
Table 3 Population parameter estimates using mixed effects modelling (standard deviation)

\begin{tabular}{|c|c|c|c|c|c|}
\hline Parameter estimates & Estimate & Inter-individual variability & Covariate tariquidar & Covariate kainate & Covariate weight \\
\hline \multicolumn{6}{|l|}{ Plasma } \\
\hline$V_{c}(m L)$ & $22.8(2.41)$ & $0.175(0.085)$ & - & - & - \\
\hline$V_{p 1}(m L)$ & $504(40.7)$ & & $1.20(0.119)$ & - & - \\
\hline$V_{p 2}(m L)$ & $70.2(9.91)$ & $0.036(0.034)$ & - & - & - \\
\hline $\mathrm{CL}\left(\mathrm{mL} \cdot \mathrm{min}^{-1}\right)$ & $14.7(0.681)$ & $0.065(0.016)$ & - & - & $1.98(0.362)$ \\
\hline $\mathrm{Q}_{1}\left(\mathrm{~mL} \cdot \mathrm{min}^{-1}\right)$ & $16.1(1.75)$ & $0.220(0.073)$ & - & - & - \\
\hline $\mathrm{Q}_{2}\left(\mathrm{~mL} \cdot \mathrm{min}^{-1}\right)$ & $22.7(3.34)$ & $0.220(0.073)$ & - & - & - \\
\hline Brain & & & - & & - \\
\hline$V_{\mathrm{br} 1}(\mathrm{~mL})$ & $7.23(2.00)$ & $0.115(0.054)$ & $2.41(0.505)$ & $1.32(0.416)$ & - \\
\hline$V_{\mathrm{br} 2}(\mathrm{~mL})$ & $10.7(2.22)$ & $0.115(0.054)$ & - & - & - \\
\hline $\mathrm{Q}_{\mathrm{in}}\left(\mathrm{mL} \cdot \mathrm{min}^{-1}\right)$ & $1.75(0.26)$ & - & $12.0(0.554)$ & - & - \\
\hline$Q_{\text {out }}\left(\mathrm{mL} \cdot \mathrm{min}^{-1}\right)$ & $1.81(0.283)$ & - & - & - & - \\
\hline $\mathrm{Q}_{\mathrm{br}}\left(\mathrm{mL} \cdot \mathrm{min}^{-1}\right)$ & $0.692(0.143)$ & - & - & - & - \\
\hline Residual errors & & & - & - & - \\
\hline blood & $0.118(0.0152)$ & - & - & - & - \\
\hline brain & $0.226(0.0354)$ & - & - & - & - \\
\hline
\end{tabular}

Covariates for tariquidar co-administration and rat group were defined as $\theta_{\text {covariate }}$ COVARIATE , where the COVARIATEs, i.e. kainate treatment or tariquidar coadministration was 1 and saline treated or vehicle co-administration 0 . The numbers reported are thus the fractional differences.

Covariate for weight was defined as (weight/0.3084) ${ }^{\theta \text { covariate }}$, where weight represent the individual animal's weight in kg and 0.3084 was the average weight among all animals. See also equations 4 and 5.

\section{P-gp expression}

P-gp expression was measured immunohistochemically and determined as P-gp labelled surface area and optical density. Results are shown in Figure 5 and 6 . The area method showed a trend towards higher P-gp expression in kainate treated rats, although the large variation resulted in a non significant difference when groups were compared with the student's t-test $(p>0.05)$. The optical density method showed no difference, not even a trend, in P-gp expression between saline and kainate treated rats.

In summary, all data analysis approaches indicated only modest differences in brain distribution of $(R)-\left[{ }^{11} \mathrm{C}\right]$ verapamil between saline and kainate treated rats. The most significant difference was in the transport rate of $(R)-\left[{ }^{11} \mathrm{C}\right]$ verapamil into the brain $\left(\mathrm{K}_{1}\right.$ and $\left.\mathrm{Q}_{\mathrm{in}}\right)$. However, this difference was only significant in the tariquidar treated groups. (R)- $\left[{ }^{11} \mathrm{C}\right]$ verapamil kinetics were best described with a two compartment plasma and two compartment brain model. Tariquidar co-administration resulted mainly in an increase of $(R)-\left[{ }^{11} \mathrm{C}\right]$ verapamil transport into the brain. NONMEM provided most precise parameter estimates. P-gp expression was found to be similar for kainate and saline treated rats.

\section{Discussion}

In this study the P-gp substrate $(R)-\left[{ }^{11} \mathrm{C}\right]$ verapamil was used in rats to investigate P-gp function at the BBB at 7 days following saline injection (control) and induction of status epilepticus (SE) by kainate. To the best of our knowledge, this is the first PET study of P-gp function at the $\mathrm{BBB}$ of kainate treated rats. In addition, it is also the first study in which PET data were analyzed both on individual data profiles using kinetic models as used routinely by the PET community, and with population mixed effects modelling, as used in the pharmacokinetic and pharmacokinetic-pharmacodynamic research field.

It has been hypothesized that P-gp expression is upregulated in epilepsy and hence contributes to the development of pharmacoresistance [10-12,21,52,53]. In the present study co-administration of $(R)-\left[{ }^{11} \mathrm{C}\right]$ verapamil with vehicle showed no or only small BBB transport differences between saline and kainate treated rats. (R)$\left[{ }^{11} \mathrm{C}\right]$ verapamil uptake in the brain was very low in both groups. A small increase in P-gp expression/function and thereby also a small decrease in $(R)-\left[{ }^{11} \mathrm{C}\right]$ verapamil uptake in kainate treated rats might not be detectable due to the already low baseline of $(R)-\left[{ }^{11} \mathrm{C}\right]$ verapamil in saline treated (control) rats. Further, due to the low baseline signal and scanner resolution the analysis was done on a whole brain region and hence possible regional differences between kainate treated and non-treated rats could therefore not be investigated.

In the present study rats were scanned one week after induction of SE by kainate. This time point was chosen because previous studies indicated that the most pronounced P-gp expression was expected around this time [24]. However, at this time point in the present study, immunohistochemical staining of P-gp expression in the hippocampus revealed only a small trend in kainate 


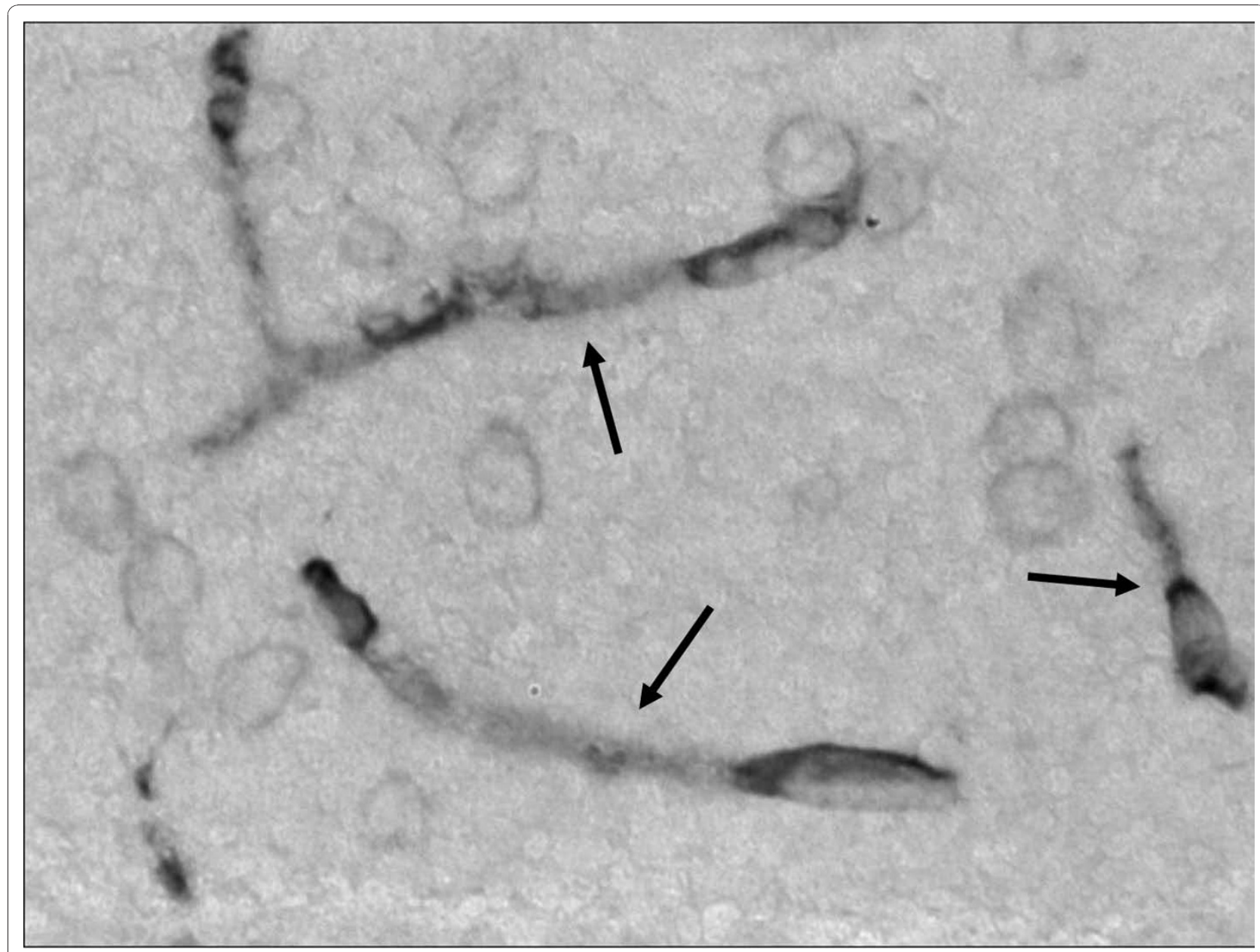

Figure 5 Staining of P-glycoprotein in the brain capillaries in the region of hippocampus. The arrows indicate the stained capillaries in a kainate treated animal.

treated rats. This was in line with P-gp functionality measured using PET, i.e. no or very small differences between the two groups. Bankstahl et al reported increase in P-gp expression at 2 days post SE induced by pilocarpine and amygdala stimulation but not at 7 days post SE [20]. On the other hand van Vliet et al, who induced SE by electrical stimulation in the dentate gyrus, and by pilocarpine reported prominent increase on both time points $[6,24]$. These variable results may thus be caused by the use of different animal models and differences experimental conditions. Further, different staining protocols emphasize P-gp expression in different cell types in the brain [41]. The immunostaining used in this study shows P-gp expression in the endothelial cells of the BBB.

Previous studies using the kainate model have shown that spontaneous seizures start to occur in the majority of rats at 3-4 weeks after SE [23]. Thus, due to the present experimental design at 7 days after induction SE by kainate it was not possible to state with certainty that the rats would develop spontaneous seizures. Nevertheless, although seizures were not yet present (apart from a few incidental observations), it can be assumed that at this time point after SE the brain is progressing towards the epileptic state. Furthermore, it is a common clinical observation that ${ }^{18} \mathrm{FDG}$ uptake is decreased in epileptic brain tissue [54]. Actually, that is also what was found in this study: a lower ${ }^{18}$ FDG brain uptake in kainate compared to saline treated rats. Therefore, this indicates that at least some functional changes were brought about in the kainate treated rats that mimics what has been observed in the human epileptic brain.

Overall, parameter estimates were similar for individual and population modelling approaches. However, for the same model complexity, mixed effects modelling provided more precise parameter estimates. This is because in population modelling, the inter-animal variability is incorporated separately from the structural model parameters. A two (tissue) compartment brain model best described cerebral kinetics of $(R)-\left[{ }^{11} \mathrm{C}\right]$ 

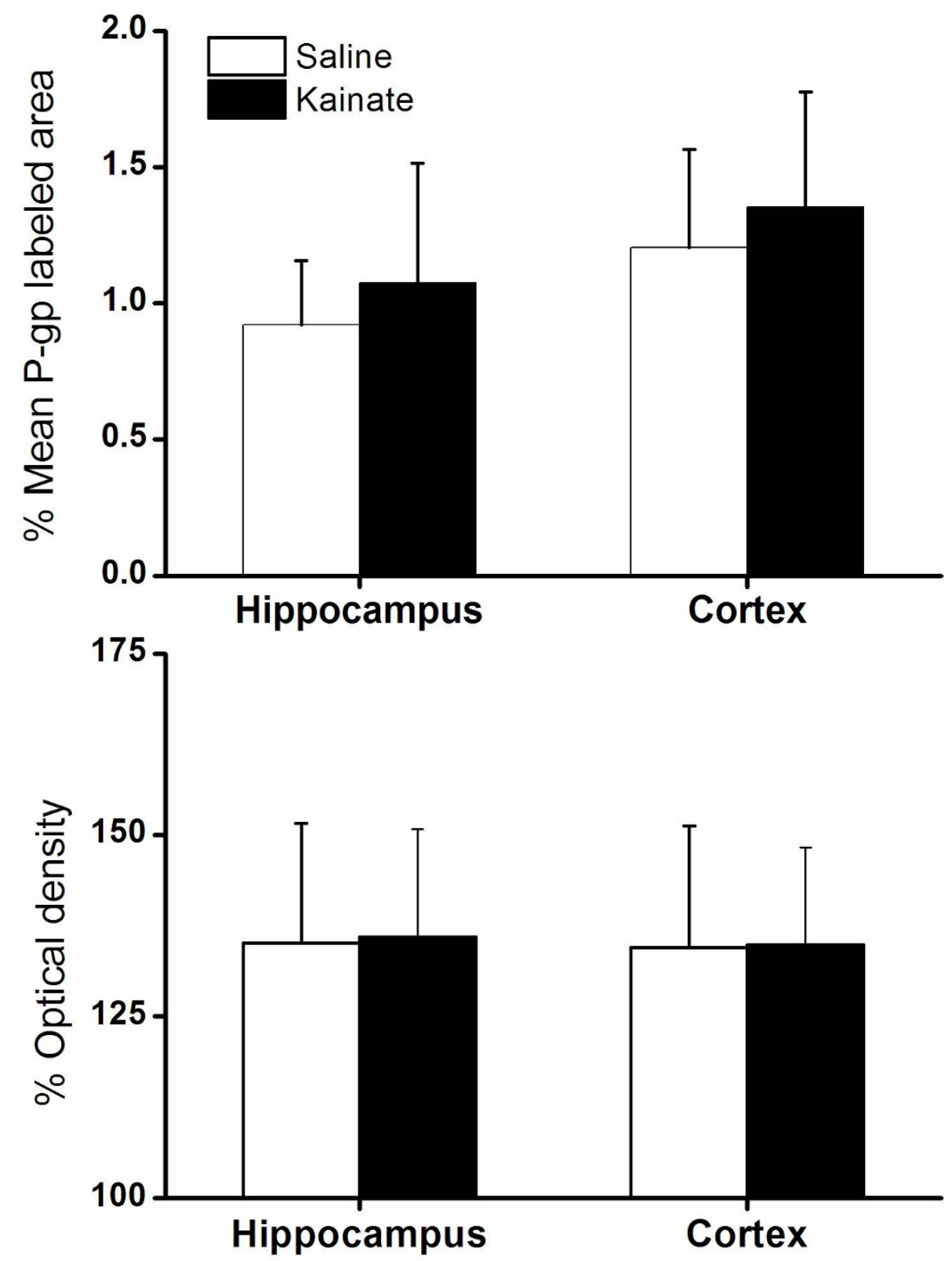

Figure 6 Mean P-gp expression measured as P-gp labelled area (upper panel) and optical density (lower panel) at 7 days after saline $(n=20)$ or kainate treatment $(n=22)$. Vertical bars represent standard deviation. There was no significant difference between the two rat groups, but the P-gp labelled area tended to be somewhat larger for kainate treated rats.

verapamil. This is in line with previous reports using $(R)-\left[{ }^{11} \mathrm{C}\right]$ verapamil in combination with a P-gp inhibitor in rats $[26,28,55]$.

Tariquidar treatment was incorporated as a categorical rather than continuous covariate in the population model. This was justified, as differences in plasma tariquidar concentrations were small and no relation between the brain-to-plasma concentration ratio, $K_{p}$, and plasma tariquidar concentration was observed. Tariquidar treatment resulted in approximately an 11-fold increase in $\mathrm{K}_{\mathrm{p}}$. This is in agreement with previous studies performed in naive (control) rats using either tariquidar or cyclosporine $\mathrm{A}$ as $\mathrm{P}$-gp inhibitor [25-28]. 
Since P-gp is expressed at the BBB, an upregulation of $\mathrm{P}$-gp function, as speculated in epilepsy, could either decrease the clearance into the brain, $\mathrm{Q}_{\text {in }}$, or increase the clearance out from the brain, $Q_{\text {out }}$. However, inclusion of rat group (saline or kainate treated) as covariate on the parameter $Q_{\text {in }}$ (which is related to $K_{1}$, the parameter usually used to describe the blood to brain transfer of PET ligands, as $\left.K_{1}=Q_{\text {in }} / \mathrm{V}_{\mathrm{c}}{ }^{*} \mathrm{~V}_{\mathrm{c}} / \mathrm{V}_{\mathrm{br} 1+2}\right)$ or on the parameter $\mathrm{Q}_{\text {out }}$ did not improve the population model fit. Instead, inclusion of rat group as covariate for the brain distribution volume, $\mathrm{V}_{\mathrm{br} 1}$, did improve the model fit significantly and increased $\mathrm{V}_{\mathrm{br} 1}$ with $32 \%$ in kainate treated compared to saline treated rats. Therefore, these data do not provide evidence of increased P-gp expression or functionality at the $\mathrm{BBB}$ at the time point after kainate treatment chosen in this study. However, in the brain P-gp is not only expressed at the endothelial cells of the BBB but also at other cell types within the brain [56]. If the kainate treatment would indeed have resulted in increased P-gp expression on brain parenchymal cells, then inhibition of P-gp expressed in brain parenchymal cells in kainate treated rats could cause a larger intracellular distribution, compared to control rats. As a consequence a $\mathrm{V}_{\mathrm{br} 1}$ would increase. This was indeed found for $(R)-\left[{ }^{11} \mathrm{C}\right]$ verapamil in the brain of kainate treated rats in the present study: the increase in $\mathrm{V}_{\mathrm{br} 1}$ resulted in a slower elimination of $(R)-\left[{ }^{11} \mathrm{C}\right]$ verapamil from the brain. However, as PET cannot distinguish between extracellular and intracellular $(R)-\left[{ }^{11} \mathrm{C}\right]$ verapamil the PET data may only indicate increased intracellular distribution. Microdialysis would be the method of choice to investigate intra-brain distribution further. In this context, the findings of Bankstahl et al. are of interest, as they reported that after SE, total brain to plasma ratio of phenytoin in rats was lower, while the opposite was found in brain dialysate to plasma ratio [20]. As discussed previously $(R)-\left[{ }^{11} \mathrm{C}\right]$ verapamil is the most frequently used radiotracer for studying $\mathrm{P}$-gp function with $\mathrm{PET}$. Recently a new radiotracer, $\left[\mathrm{N}\right.$-methyl $\left.{ }^{11} \mathrm{C}\right] \mathrm{N}$-desmethyl-loperamide has been developed [57]. This radiotracer could potentially be better suited for studying $\mathrm{P}$-gp function since it produces less radiolabelled metabolites compared to $(R)-\left[{ }^{11} \mathrm{C}\right]$ verapamil and hence gives a purer signal. The problem with a low baseline signal still remains with this novel tracer. Bartmann et al used the $5 \mathrm{HT}_{1 \mathrm{~A}}$ receptor ligand $\left[{ }^{18} \mathrm{~F}\right] \mathrm{MPPF}$ (fluorine-18labeled4-(2;-methoxyphenyl)-1-[2;-(N-2"-pirydynyl)-p fluorobenzamido]ethylpiperazine) to study brain uptake in a chronic rat model of epilepsy and found that tariquidar treatment increased the transport into and decreased the transport out from the brain more in AED non-responders compared to AED responder rats [58]. This is in line with the notion that AED non-responders have an increased P-gp functionality compared to AED responders. The advantage of using a receptor ligand such as $\left[{ }^{18} \mathrm{~F}\right] \mathrm{MPPF}$ is that the baseline brain penetration is higher compared to $(R)-\left[{ }^{11} \mathrm{C}\right]$ verapamil and [N-methyl$\left.{ }^{11} \mathrm{C}\right] \mathrm{N}$-desmethyl-loperamide. However, binding to receptors within the brain might potentially confound the results.

Finally, changes in blood flow due to tariquidar treatment or disease state could potentially confound the results if brain distribution of $(R)-\left[{ }^{11} C\right]$ verapamil would be limited by blood flow. There are, however, no studies indicating that tariquidar would alter blood flow and there are no studies comparing blood flow in kainate treated rats compared to controls.

\section{Conclusions}

In tariquidar co-administered animals, a decrease in brain uptake of $(R)-\left[{ }^{11} C\right]$ verapamil was observed in kainate treated compared to saline treated rats in an early phase of 7 days following induction of SE. However, the clearance out of the brain was also slower in the kainate treated rats, resulting in similar brain-to-blood ratios $\left(K_{\mathrm{p}}\right)$ for both groups. No significant changes in P-gp expression were found. Further investigations have to show if P-gp expression/functionality is altered in a later stage of epilepsy development.

\section{Acknowledgements}

We thank Maarten Schenke and Inge de Greeuw for assistance with animal surgery and operating the PET scanner, respectively. We are also grateful to Robert Schuit and Kevin Takkenkamp for metabolite analysis, Nikie Hoetjes for assistance with the reconstruction of the PET data, Maaike Labots for the P-gp expression analysis and Anneloes Rijnders, Janet Schepers and Martien Mooijer for $(R)-\left[{ }^{11} C\right]$ verapamil syntheses. This work was supported by the EU $7^{\text {th }}$ framework programme EURIPIDES (FP7/2007-2013 under grant agreement $n^{\circ}$ 201380)

\section{Author details}

'Division of Pharmacology, LACDR, Leiden University, P.O. Box 9502, 2300 RA Leiden, The Netherlands. ${ }^{2}$ Department of Nuclear Medicine \& Molecular Imaging, Groningen University Medical Center, P.O. Box 30.0019700 RB Groningen, The Netherlands. ${ }^{3}$ Department of Nuclear Medicine \& PET Research, VU University Medical Center, P.O. Box 7057, 1007 MB, Amsterdam, The Netherlands. ${ }^{4}$ Epilepsy Institute of The Netherlands Foundation (SEIN), P. O. Box 21, 2100 AA, Heemstede, The Netherlands.

\section{Authors' contributions}

SS, ECL and RAV planned the study. ADW and GL were responsible for radiochemistry and metabolite analysis, respectively. SS, GL and CFMM organized and performed the animal studies. MCH was responsible for the PET scanner. SS performed the data analysis with assistance from $\mathrm{MCH}$ and AAL. SS, ECL and RAV wrote the manuscript. All authors read and approved the final manuscript.

\section{Competing interests}

The authors declare that they have no competing interests.

Received: 21 May 2010 Accepted: 3 January 2011

Published: 3 January 2011

\section{References}

1. Schmidt D, Löscher W: Drug resistance in epilepsy: putative neurobiologic and clinical mechanisms. Epilepsia 2005, 46(6):858-877. 
2. Regesta G, Tanganelli P: Clinical aspects and biological bases of drugresistant epilepsies. Epilepsy Res 1999, 34(2-3):109-122.

3. Cordon-Cardo C, O'Brien JP, Casals D, Rittman-Grauer L, Biedler JL, Melamed MR, Bertino JR: Multidrug-resistance gene (P-glycoprotein) is expressed by endothelial cells at blood-brain barrier sites. Proc Natl Acad Sci USA 1989, 86(2):695-698.

4. Schinkel AH, Jonker JW: Mammalian drug efflux transporters of the ATP binding cassette (ABC) family: an overview. Adv Drug Deliv Rev 2003, 55(1):3-29.

5. Brandt C, Bethmann K, Gastens AM, Loscher W: The multidrug transporter hypothesis of drug resistance in epilepsy: Proof-of-principle in a rat model of temporal lobe epilepsy. Neurobiol Dis 2006, 24(1):202-211.

6. van Vliet EA, Zibell G, Pekcec A, Schlichtiger J, Edelbroek PM, Holtman L, Aronica E, Gorter JA, Potschka H: COX-2 inhibition controls P-glycoprotein expression and promotes brain delivery of phenytoin in chronic epileptic rats. Neuropharmacology 2009, 58(2):404-412.

7. Rizzi M, Caccia S, Guiso G, Richichi C, Gorter JA, Aronica E, Aliprandi M, Bagnati $R$, Fanelli $R$, D'Incalci $M$, et al: Limbic seizures induce Pglycoprotein in rodent brain: functional implications for pharmacoresistance. J Neurosci 2002, 22(14):5833-5839.

8. Hocht C, Lazarowski A, Gonzalez NN, Auzmendi J, Opezzo JA, Bramuglia GF, Taira CA, Girardi E: Nimodipine restores the altered hippocampal phenytoin pharmacokinetics in a refractory epileptic model. Neurosci Lett 2007, 413(2):168-172, Epub 2007 Jan 2008.

9. Hocht C, Lazarowski A, Gonzalez NN, Mayer MA, Opezzo JA, Taira CA, Girardi E: Differential hippocampal pharmacokinetics of phenobarbital and carbamazepine in repetitive seizures induced by 3 mercaptopropionic acid. Neurosci Lett 2009, 453(1):54-57, Epub 2009 Feb 2004

10. Sisodiya SM, Lin WR, Harding BN, Squier MV, Thom M: Drug resistance in epilepsy: expression of drug resistance proteins in common causes of refractory epilepsy. Brain 2002, 125(Pt 1):22-31.

11. Tishler DM, Weinberg KI, Hinton DR, Barbaro N, Annett GM, Raffel C: MDR1 gene expression in brain of patients with medically intractable epilepsy. Epilepsia 1995, 36(1):1-6.

12. Dombrowski SM, Desai SY, Marroni M, Cucullo L, Goodrich K, Bingaman W, Mayberg MR, Bengez L, Janigro D: Overexpression of multiple drug resistance genes in endothelial cells from patients with refractory epilepsy. Epilepsia 2001, 42(12):1501-1506

13. van Vliet EA, van Schaik R, Edelbroek PM, Redeker S, Aronica E, Wadman WJ, Marchi N, Vezzani A, Gorter JA: Inhibition of the multidrug transporter P-glycoprotein improves seizure control in phenytoin-treated chronic epileptic rats. Epilepsia 2006, 47(4):672-680.

14. Löscher W, Potschka H: Role of drug efflux transporters in the brain for drug disposition and treatment of brain diseases. Prog Neurobiol 2005, 76(1):22-76

15. Luna-Tortos C, Rambeck B, Jurgens UH, Loscher W: The Antiepileptic Drug Topiramate is a Substrate for Human P-glycoprotein but Not Multidrug Resistance Proteins. Pharm Res 2009, 3:3.

16. Sisodiya SM, Heffernan J, Squier MV: Over-expression of P-glycoprotein in malformations of cortical development. Neuroreport 1999, 10(16):3437-3441.

17. Löscher W, Potschka H: Role of multidrug transporters in pharmacoresistance to antiepileptic drugs. J Pharmacol Exp Ther 2002, 301(1):7-14.

18. Robey RW, Lazarowski A, Bates SE: P-glycoprotein-a clinical target in drug-refractory epilepsy? Mol Pharmacol 2008, 73(5):1343-1346.

19. Pekcec A, Unkruer B, Stein V, Bankstahl JP, Soerensen J, Tipold A, Baumgartner W, Potschka H: Over-expression of P-glycoprotein in the canine brain following spontaneous status epilepticus. Epilepsy Res 2009, 83(2-3):144-151.

20. Bankstahl JP, Löscher W: Resistance to antiepileptic drugs and expression of P-glycoprotein in two rat models of status epilepticus. Epilepsy Res 2008, 82(1):70-85.

21. Löscher W: How to explain multidrug resistance in epilepsy? Epilepsy Curr 2005, 5:107-112

22. Anderson GD, Shen DD: Where is the evidence that p-glycoprotein limits brain uptake of antiepileptic drug and contributes to drug resistance in epilepsy? Epilepsia 2007, 48(12):2372-2374

23. Hellier JL, Patrylo PR, Buckmaster PS, Dudek FE: Recurrent spontaneous motor seizures after repeated low-dose systemic treatment with kainate: assessment of a rat model of temporal lobe epilepsy. Epilepsy Res 1998, 31(1):73-84

24. van Vliet E, Aronica E, Redeker S, Marchi N, Rizzi M, Vezzani A, Gorter J: Selective and persistent upregulation of mdr1b mRNA and Pglycoprotein in the parahippocampal cortex of chronic epileptic rats. Epilepsy Res 2004, 60(2-3):203-213.

25. Bart J, Willemsen AT, Groen HJ, van der Graaf WT, Wegman TD, Vaalburg W, de Vries EG, Hendrikse NH: Quantitative assessment of P-glycoprotein function in the rat blood-brain barrier by distribution volume of $\left[{ }^{11} \mathrm{C}\right]$ verapamil measured with PET. Neuroimage 2003, 20(3):1775-1782.

26. Bankstahl JP, Kuntner C, Abrahim A, Karch R, Stanek J, Wanek T, Wadsak W, Kletter K, Muller M, Löscher W, et al: Tariquidar-induced P-glycoprotein inhibition at the rat blood-brain barrier studied with (R)-11C-verapamil and PET. J NuCl Med 2008, 49(8):1328-1335.

27. Hendrikse NH, de Vries EG, Eriks-Fluks L, van der Graaf WT, Hospers GA, Willemsen AT, Vaalburg W, Franssen EJ: A new in vivo method to study Pglycoprotein transport in tumors and the blood-brain barrier. Cancer Res 1999, 59(10):2411-2416.

28. Syvänen S, Blomquist G, Sprycha M, Höglund AU, Roman M, Eriksson O, Hammarlund-Udenaes $\mathrm{M}$, Långström $\mathrm{B}$, Bergström M: Duration and degree of cyclosporin induced P-glycoprotein inhibition in the rat blood-brain barrier can be studied with PET. Neuroimage 2006, 32(3):1134-1141.

29. Sasongko L, Link JM, Muzi M, Mankoff DA, Yang X, Collier AC, Shoner SC, Unadkat JD: Imaging P-glycoprotein transport activity at the human blood-brain barrier with positron emission tomography. Clin Pharmacol Ther 2005, 77(6):503-514.

30. Lee YJ, Maeda J, Kusuhara H, Okauchi T, Inaji M, Nagai Y, Obayashi S, Nakao R, Suzuki K, Sugiyama Y, et al: In vivo evaluation of P-glycoprotein function at the blood-brain barrier in nonhuman primates using $\left[{ }^{11} \mathrm{C}\right]$ verapamil. J Pharmacol Exp Ther 2006, 316(2):647-653.

31. Toornvliet $R$, van Berckel BN, Luurtsema G, Lubberink M, Geldof AA, Bosch TM, Oerlemans R, Lammertsma AA, Franssen EJ: Effect of age on functional P-glycoprotein in the blood-brain barrier measured by use of (R)-[( $\left[{ }^{11}\right)$ C]verapamil and positron emission tomography. Clin Pharmacol Ther 2006, 79(6):540-548.

32. Ikoma Y, Takano A, Ito H, Kusuhara H, Sugiyama Y, Arakawa R, Fukumura T, Nakao R, Suzuki K, Suhara T: Quantitative analysis of 11C-verapamil transfer at the human blood-brain barrier for evaluation of $\mathrm{P}$ glycoprotein function. J Nucl Med 2006, 47(9):1531-1537.

33. Kortekaas R, Leenders KL, van Oostrom JC, Vaalburg W, Bart J, Willemsen AT, Hendrikse NH: Blood-brain barrier dysfunction in parkinsonian midbrain in vivo. Ann Neurol 2005, 57(2):176-179.

34. Langer O, Bauer M, Hammers A, Karch R, Pataraia E, Koepp MJ, Abrahim A Luurtsema G, Brunner M, Sunder-Plassmann R, et al: Pharmacoresistance in epilepsy: a pilot PET study with the P-glycoprotein substrate R-[(11)C] verapamil. Epilepsia 2007, 48(9):1774-1784.

35. Racine R, Okujava V, Chipashvili S: Modification of seizure activity by electrical stimulation. 3. Mechanisms. Electroencephalogr Clin Neurophysiol 1972, 32(3):295-299.

36. Luurtsema G, Windhorst AD, J. MP, Herscheid JDM, Lammertsma AA, Franssen EJ: Fully automated high yield synthesis of (R)- and (S)-[11C] verapamil for measuring the P-glycoprotein function with positron emission tomography. J Labelled Compd Radiopharm 2002, 45:1199-1207.

37. de Jong HW, van Velden FH, Kloet RW, Buiis FL, Boellaard R, Lammertsma AA: Performance evaluation of the ECAT HRRT: an LSOLYSO double layer high resolution, high sensitivity scanner. Phys Med Biol 2007, 52(5):1505-1526.

38. van Velden $F H$, Kloet RW, van Berckel BN, Molthoff $C F$, de Jong HW, Lammertsma AA, Boellaard R: Impact of attenuation correction strategies on the quantification of High Resolution Research Tomograph PET studies. Phys Med Biol 2008, 53(1):99-118.

39. van Velden FH, Kloet RW, van Berckel BN, Buijs FL, Luurtsema G, Lammertsma AA, Boellaard R: HRRT Versus HR+ Human Brain PET Studies: An Interscanner Test-Retest Study. J Nucl Med 2009, 50(5):693-702.

40. Luurtsema G, Molthoff CF, Schuit RC, Windhorst AD, Lammertsma AA, Franssen EJ: Evaluation of (R)-[11C]verapamil as PET tracer of Pglycoprotein function in the blood-brain barrier: kinetics and metabolism in the rat. Nucl Med Biol 2005, 32(1):87-93.

41. Volk H, Potschka H, Loscher W: Immunohistochemical localization of Pglycoprotein in rat brain and detection of its increased expression by 
seizures are sensitive to fixation and staining variables. $J$ Histochem Cytochem 2005, 53(4):517-531.

42. Paxinos G, Watson C: The Rat Brain in stereotaxic coordinates. New York Academic Press; 21986.

43. Abramoff MD, Magelhaes PJ, Ram SJ: Image Processing with ImageJ. Biophotonics International 2004, 11(7):36-42.

44. Loening AM, Gambhir SS: AMIDE: A free software tool for multimodality medical image analysis. Mol Imaging 2003, 2:131-137.

45. Todd MM, Weeks JB, Warner DS: Cerebral blood flow, blood volume, and brain tissue hematocrit during isovolemic hemodilution with hetastarch in rats. Am J Physiol 1992, 263(1 Pt 2):H75-82.

46. Lubberink M, Luurtsema G, van Berckel BN, Boellaard R, Toornvliet R, Windhorst AD, Franssen EJ, Lammertsma AA: Evaluation of tracer kinetic models for quantification of P-glycoprotein function using (R)-[11C] verapamil and PET. J Cereb Blood Flow Metab 2007, 27(2):424-433.

47. Logan J, Fowler JS, Volkow ND, Wolf AP, Dewey SL, Schlyer DJ, MacGregor RR, Hitzemann R, Bendriem B, Gatley SJ, et al: Graphical analysis of reversible radioligand binding from time-activity measurements applied to [N-11C-methyl]-(-)-cocaine PET studies in human subjects. J Cereb Blood Flow Metab 1990, 10(5):740-747.

48. Gunn RN, Gunn SR, Cunningham VJ: Positron emission tomography compartmental models. J Cereb Blood Flow Metab 2001, 21(6):635-652

49. Akaike $\mathrm{H}$ : A new look at the statistical model identification. IEEE Trans Autom Control 1974, 19:716-723.

50. Jonsson EN, Karlsson MO: Xpose - an S-PLUS based population pharmacokinetic/pharmacodynamic model building aid for NONMEM. Computer Methods and Programs in Biomedicine 1999, 58(1):51-64.

51. Wilkins JJ: NONMEMory: a run management tool for NONMEM. Comput Methods Programs Biomed 2005, 78(3):259-267.

52. Zibell G, Unkruer B, Pekcec A, Hartz AM, Bauer B, Miller DS, Potschka H: Prevention of seizure-induced up-regulation of endothelial $P$ glycoprotein by COX-2 inhibition. Neuropharmacology 2009, 56(5):849-855.

53. Potschka $\mathrm{H}$ : Targeting regulation of $A B C$ efflux transporters in brain diseases: a novel therapeutic approach. Pharmacol Ther 2009, 125(1):118-127.

54. Henry TR, Votaw JR: The role of positron emission tomography with [18F] fluorodeoxyglucose in the evaluation of the epilepsies. Neuroimaging Clin N Am 2004, 14(3):517-535, ix.

55. Syvänen $\mathrm{S}$, Hooker $\mathrm{A}$, Rahman $\mathrm{O}$, Wilking $\mathrm{H}$, Blomquist $\mathrm{G}$, Långström $\mathrm{B}$, Bergström M, Hammarlund-Udenaes M: Pharmacokinetics of Pglycoprotein inhibition in the rat blood-brain barrier. J Pharm Sci 2008, 97(12):5386-5400.

56. Ronaldson PT, Persidsky $Y$, Bendayan R: Regulation of $A B C$ membrane transporters in glial cells: relevance to the pharmacotherapy of brain HIV-1 infection. Glia 2008, 56(16):1711-1735.

57. Lazarova N, Zoghbi SS, Hong J, Seneca N, Tuan E, Gladding RL, Liow JS, Taku A, Innis RB, Pike WW: Synthesis and evaluation of [N-methyl-11C]Ndesmethyl-loperamide as a new and improved PET radiotracer for imaging P-gp function. J Med Chem 2008, 51(19):6034-6043.

58. Bartmann $H$, Fuest $C$, La Fougere $C$, Xiong G, Just $T$, Schlichtiger J, Winter $P$, Boning G, Wangler B, Pekcec A, et al: Imaging of P-glycoprotein-mediated pharmacoresistance in the hippocampus: Proof-of-concept in a chronic rat model of temporal lobe epilepsy. Epilepsia 2010, 51(9):1780-1790.

\section{Pre-publication history}

The pre-publication history for this paper can be accessed here: http://www.biomedcentral.com/1471-2342/11/1/prepub

doi:10.1186/1471-2342-11-1

Cite this article as: Syvänen et al:: $(R)-\left[{ }^{11} \mathrm{C}\right]$ Verapamil PET studies to assess changes in P-glycoprotein expression and functionality in rat blood-brain barrier after exposure to kainate-induced status epilepticus. BMC Medical Imaging 2011 11:1.

\section{Submit your next manuscript to BioMed Central and take full advantage of:}

- Convenient online submission

- Thorough peer review

- No space constraints or color figure charges

- Immediate publication on acceptance

- Inclusion in PubMed, CAS, Scopus and Google Scholar

- Research which is freely available for redistribution

Submit your manuscript at www.biomedcentral.com/submit
Ciomed Central 